Yueguo $\mathrm{Gu}^{*}$

\title{
ChinaCALL in retrospect and prospect: opening a welcome window to the World's CALLs
}

https://doi.org/10.1515/jccall-2021-2001

Received March 29, 2021; accepted July 5, 2021; published online September 6, 2021

\begin{abstract}
This paper, while sending a welcome message to the world's CALL communities, presents a historical and developmental review of Chinese practices of educational technologies and ChinaCALL in particular. The review covers topics including the birth and concept of ChinaCALL, ChinaCALL's pre-CALL heritage, pre-Web ChinaCALL, ChinaCALL in the new millennium, IBOE as a case study of ChinaCALL, and ChinaCALL in prospect. Also discussed are Chinese perceptions of educational technologies occurring at the macro, the meso and ground levels. On the ground level, technology consumers are characterized in terms of pen-pencil conservatives, AV natives, AV-CALL immigrants, CALL natives and CALL standby observers.
\end{abstract}

Keywords: AV-CALL immigrants; AV natives; CALL natives; ChinaCALL; pre-CALL heritage

\section{Preliminary remarks}

It has long been a wish of members that ChinaCALL had an academic journal of its own. Today it has become a reality. Members' appreciation for the two publishers, viz. de Gruyter and Foreign Language Teaching and Research Press (FLTRP), of their professional assistance is here heartedly voiced.

This paper is intended to serve three concurrent purposes. The first is ceremonial, that is, to send, in my capacity of ChinaCALL presidency, a welcome message to global CALL practitioners, emphasizing the fact that the Journal of ChinaCALL is by design an academic platform for global communities. The second is personal in the sense that the retrospective aspect of the paper is made from the perspective of a reflective practitioner, i.e., an experimenter in the ChinaCALL field

*Corresponding author: Yueguo Gu, Beijing Foreign Studies University, Beijing, China, E-mail: gyg@beiwaionline.com 
for the last three decades. The third, the central one, is to sketch a historical landscape of the growth and development of ChinaCALL, a sort of map, as it were, for those who are interested in knowing something about ChinaCALL itself.

Before heading into details, a word about terminology is in order. The acronym CALL, viz. computer-assisted language learning, is no longer used literally as a multi-word compound with its sense derived from its component words. It acts as a shortcut term, for the sake of brevity and convenience, and includes computerassisted instruction (CAI), computer-assisted language teaching (CALT), computer-assisted language testing (CALT), as well as e-learning. Moreover, also put under its rubric are PC-based CALL as well as Web-based CALL. This broader usage of CALL is justified on the ground that international CALL conferences and associations' names such as PacCALL, AsiaCALL, WorldCALL, etc., all have given it a very broad interpretation, as suggested here. In a way CALL functions more as a technical term by itself than an acronym.

The paper will evolve as follows. First Levy's review of CALL evolution in the world is cited as a global context in which ChinaCALL is embedded (Section 2). Developmental landmarks of ChinaCALL are outlined in Section 3. ChinaCALL, sharing the world's common CALL technologies, has its own characteristics embodied in Chinese perceptions of technologies and practices of employing them (Section 4). This is followed by a case of study of ChinaCALL, an in-depth look at the Institute of Beiwai Online Education (Section 5). The last two Sections 6 through 7 present ChinaCALL in retrospect and prospect respectively.

\section{ChinaCALL in the context of the World's CALLs}

Levy (1997: 13-46) reviewed the historical development of CALL in the world context by focusing on selected CALL projects representative of three periods, the 1960s and 1970s, the 1980s, and the 1990s. CALL in the 1960s and 1970s was, on the technology side, marked by projects tended to involve mainframe computers and large-scale systems, since the wide spread use of microcomputers was a much later event. The two most prominent projects were the PLATO and TICCIT projects, both of which were used to teach foreign languages as well as other subjects.

The 1980s saw a boom in CALL largely due to the introduction of the microcomputer. Introductory books on the topic began to appear, and specialized CALL journals, such as the CALICO Journal first appeared (1983). As the hardware of microcomputers became increasingly cheaper, and programming languages became intelligible to technology-minded teachers, language teachers started to play a more active role in designing and writing CALL programs. 
CALL in the 1990s, while the development of the microcomputer in the 1980s gave impetus to extensive adoption of CALL as a viable teaching methodology, witnessed the emergence of the Internet, which would exert an ever-lasting impact on CALL development and expansion. Projects that initially required expensive, specialized hardware, soon became available to all those who were given access through networked microcomputers.

Also in the 1990s, the combination of the microcomputer and the network technology gave rise to extensive practice of setting up self-access centres for self-access learning. Historically speaking, there are two generations of self-access centres. One is traditional, that is, print books, audio, video analogue cassettes, radio and TV programmes are collected together and pedagogically categorized for learners to have free access to with or without a teacher/facilitator's assistance. The other is local administered network (LAN) supported. That is, print and multimedia resources are digitalized and made available through a group of microcomputers connected to form a LAN. Self-access centres of both generations are found in major universities in Europe, North America, Australia, Southeast Asia, China's Hong Kong and China's Taiwan (see Benson \& Voller, 1997; Esch, 1994; Gardner \& Miller, 1999; Huang \& Gu, 1996).

When the world's CALLs entered the new millennium they were overwhelmed by a plethora of new technologies. As Kinshuk (2009: xii) observes, "technology first, pedagogy later"... "is not new when it comes to technology adoption in education." Among these, wearable and handy devices have readily caught the imagination of educators all over the world. The concept of mobile learning is viewed by some (e.g. Kalz, Bayyurt \& Specht, 2014) as representing a new "mainstream". It is worth noting at this point that the

rapid growth of mobile learning has its roots as much in the educational and pedagogical needs of flexibility and the anytime anywhere demand for learning as it does in the readily available mass market of tiny devices that almost everyone seems to have [emphasis added] (Kinshuk, 2009: xii).

This review, being skeleton and oversimplistic, cannot be complete without mentioning a the massive open online course (MOOC) boom. MOOCs do not stand for a new technology in the way mobile devices do - they are a reformed way of delivering courses. Tracking the historical roots of MOOCs, Pomerol, Epelboin, and Thoury (2015, pp.4-5) concluded that "MOOCs are distance learning as the order of the day".

Against the backdrop of the world's CALLs, the CALL projects in the 1960 s and 1970s Levy depicted were unknown in China. China only began to experiment CALL projects in the 1980s. However, there is a much longer history of pre-CALL learning through analogue media in China, i.e., predecessor of ChinaCALL. 


\section{ChinaCALL: landmarks of development}

\subsection{ChinaCALL: concept and birth}

ChinaCALL designates a relational concept, the meaning of which is delineated by its relations with the world's CALL at large. In other words, ChinaCALL functions as part of the global community in the way PacCALL, EuroCALL, KoreanCALL, JapanCALL, etc. do. It is also to some extent a substantial concept, since ChinaCALL stands for an academic association officially launched at its first official conference held in 2000 with over 110 attendees representing about 80 different tertiary institutions as well as some business sectors. In the ensuing years, ChinaCALL organized first annual, then bi-annual conferences. As of the writing of this article, there have been 16 conferences altogether.

ChinaCALL was initially registered as a sub-branch of China English Language Teaching \& Research Association, and was re-assigned in 2019 as an affiliate of China Association for Comparative Studies of English and Chinese. The Journal of ChinaCALL is considered as the Association's mouthpiece through which its members' research activities and outcomes are articulated and shared with global colleagues.

The concept of ChinaCALL arguably first appeared as a conference theme in 1993 when colleagues and I attempted to organize a CALL conference in BFSU, only to be attended, very disappointedly, by a dozen participants. We were partly motivated by the prospect of competing for an international project, which required track records of some sorts. Eventually we won and in 1996, the then School of English Language Communication, BFSU, of which I was the dean, established a LAN-supported self-access centre consisting of 25 networked microcomputers sponsored by Flemish Government of Belgium.

The warm-up ChinaCALL conference, a misnomer at best, was not a downright failure. It had stirred waves of interest among tertiary education colleagues. More crucially, the 25 LAN-networked microcomputers functioned as a self-access centre for another project the School won from the then British Council, viz. the Sino-UK Project of DT-SMSTT (i.e., distance taught senior middle school teacher training). The DT-SMSTT was initially designed and later actually implemented in the traditional distance learning mode. The uplifting of the DT-SMSTT to the CALL mode of delivery was whole-heartedly embraced by the Sino-UK project stakeholders. The present Institute of Beiwai Online Education, with over hundred thousands of registered students, was established in the year 2000 based on the materials and local partner institutions for the DT-SMSTT. 
In retrospect, the aforementioned poor attendance of ChinaCALL was partly due to the disciplinary territorial boundaries intrinsic to the departmentalization of academic knowledge, a global practical dominance, and partly due to my personal ignorance of the then broader Chinese context, since I was a five-year returnee to China from my $\mathrm{Ph}$.D. studies in the UK. China had a fairly long track record of pre-CALL learning by analogue audio-video media. The rallying concept was instruction/learning by educational technology. The Chinese native term generally used was dianhua jiaoyu (电化教育, AV education), the first adoption of which was dated as early as 1933 (Xiao, 1983: 2). When People's Republic of China was founded in 1949, dianhua jiaoyu was considered so important that a special committee under the State Council was appointed to coordinate national efforts in utilizing educational technologies (ETs).

Hence, a brief historical tour into pre-CALL practice in China is helpful. It will become clear that the pre-CALL practice cannot, and should not be swept under the carpet of historical ashes, as it is wittingly or subconsciously inherited by the present CALL theories and practices. Furthermore, some "good old days" ETs, outdated in terms of mechanics and complexity, are still in use.

\subsection{AV education: ChinaCALL's pre-CALL heritage}

Educationally speaking, the closest predecessor of ChinaCALL is AV-based education which was implemented using a variety of devices such as radio receivers, projectors, analogue audio and video cassettes and players, films, etc. Educational technologies were appreciated, at the dawn of the founding of the PRC, as possessing a special force that could be mobilized to modernize the then poorly-equipped educational system. AV education pilots were launched in 1958, and voices for reforms of the contemporary educational practice using AV education as leverage were heard in the second People's National Conference. The AV education movement soon ran out of steam thanks to the ensuing economic crises followed by the Cultural Revolution (Xiao, 1983, p. 14).

AV education was revived in 1978 when China was preparing itself for reforms and opening-up. AV education once more was regarded as an important strategy for social and economic development. Secondary and tertiary institutions all over China started to allocate special funds and human resources for establishing AV education centres. The year 1979 was destined to be remembered for the founding of China Radio and TV University (CRTVU, Liu, 1990, p. 344) - now renamed Open University China (OUC) - the largest university ever in the world in view of the number of enrolled students and its provincial branches subsequently set up throughout China. 
What is significant, as far as ChinaCALL is concerned, is that AV education centres were no later set up than courses of foreign language teaching/learning were offered. It was taken for granted that AV methods provided best vicarious experiences for foreign language learners. As a consequence, AV education was provided in two different faculties: educational technology, and foreign languages. Each faculty facilitated its own activities both intra-institutionally and inter-institutionally nationwide. This man-made interdisciplinary boundary was rarely crossed until recently.

\subsection{Early ChinaCALL: pre-web CALL phases of development}

From roughly 1979 towards the end of the twentieth century, ChinaCALL could be characterized as pre-Web CALL. The main driving force came from three faculties, viz. AV education, foreign languages and computer science. Many educational breakthroughs stood out, because they represented robust reforms, i.e., counter-measures against the academic downfalls experienced in the previous decade. CALL was taught as a credit-bearing regular course in both fourand three-year tertiary education systems. This created demands for CALL textbooks, e.g., Liu (1988), Shi (2001) - mainly about how to edit digital multimedia for delivering audio and video instructional materials. Funds were also made available for research activities. As a consequence, research institutes, academic associations and journals were established. The Journal of $A V$ Education for Foreign Languages (waiyu dianjiao 外语电教) sponsored by Shanghai Foreign Languages Institute has stood the test of time. Presently its Chinese title has changed into Waiyu dianhua jiaoxue (外语电化教学), and its English title has become Computer-assisted Foreign Language Education (CAFLE). The CRTVU/OUC also launched two journals of its own, viz. Distance Education in China (Zhongguo yuancheng jiaoyu 中国远程教育), and E-Learning (Zaixian xuexi 在线学习).

\subsection{ChinaCALL: a millennium web-based CALL boom}

Web-based CALLs at the nationwide scale were first piloted in 1994 with four universities (Tsinghua University, Hunan University, Zhejiang University and Beijing Post and Communications University) authorized by the Ministry of Education (the MoE), each of which set up a piloting faculty that would run pilot e-learning programmes with the goal of gaining experiences for the later 
wide-scale launching, which did take place in 1999. During the subsequent four years, 64 more piloting faculties (known as online education colleges, or e-learning institutes, or online education institutes) had been established by the host universities. Business sectors were allowed to be stakeholders providing funding for some piloting faculties (for more details see Kang \& Song, 2007).

The infrastructures, including telematic technologies and infohighways, for the 68 online education faculties, are in large part provided by the central or local governments. China Education and Research Network (CERNET), for instance, is a government-sponsored national network that is open to high education sectors throughout China. It is to the cyberspace that 68 faculties make their own contributions. It is also the cyberspace where learning and instructions take place.

The world's MOOC boom also hit China, most noticeably in 2017, when China MOOCs for Foreign Studies (UMOOCs), with initial 183 contracted institutions, was officially announced, and coordinated by BFSU. It is worth noting that there is a significant difference between the MoE's online education initiative and the UMOOCs association initiative. The outcome of the former is the establishment of online education faculties that have become part of the host institution's regular structure. The latter, lacking the former's top-level authority, is managed on the like-mind bases. Like-minds can change their mind, which will impact the function of the UMOOC Association.

\subsection{Recap}

The Chinese term jiaoyu jishu (教育技术, educational technology) has been used as an umbrella term that covers all the media employed for instructional purposes. It is divided into two general classes: analogue and digital. Both classes are further divided into two sub-classes: static (for orthographic texts, still images, etc.) and dynamic (for audio/video streams, animations, etc.). It is important to note that CALL technologies, LAN or Internet, are regarded as natural update additions to the existing inventory. Analogue static/dynamic media, some gradually fading out though, are still found in use in China. Most noticeably, print-text books are preferred by some users. Even some of my $\mathrm{PhD}$ students preferred to print the e-books I gave them to read. The reason for that, so I was told, is that print books are rongyi ji (容易记), viz. easier to remember. Digital static/dynamic media, on the other hand, have become dominant, and especially web-supported and mobile media have permeated almost all spheres of everyday life.

Both classes of media devices may be made in China, but not of China, except for the paper, the ancient China's invention. At the risk of making sweeping 
generalizations, all modern educational technologies were invented by the Western world, and were globally adopted. Technological universality, however, does not mean that ChinaCALL bears no distinctive hallmarks of its own. What makes ChinaCALL distinctive among its global CALL companions lies in the Chinese ways of perceiving the technologies and acting accordingly.

Bear in mind, though, that Chinese perceptions of ChinaCALL will be addressed in terms of Chinese perceptions of ETs in general (Section 4 below), because jiaoyu jishu is an umbrella term extensively used in government policy statements, mass media, institutional daily management discourse, etc. In contrast, CALL or ChinaCALL is a special terminology only understood by a limited circle.

\section{ChinaCALL's information infrastructure: perceptions and actions}

It would be a mistake to assume that Chinese ET perception is monolithic. On the contrary, perceptions of technology, as everywhere, are remarkably varied and diversified. Chinese ET perceptions are to be examined in terms of three levels of social-political-economical structure: (1) the national level; (2) the organizational/ institutional level; and (3) the ground level of individual users. Individual users will be characterized in four groups:

1) Conservatives, i.e., those who stick to the paper-pen style of learning/instruction;

2) AV natives, ${ }^{1}$ i.e., those who are used to and constrained by, willingly or otherwise, AV technology only;

3) AV-to-CALL immigrants, i.e., those who, though used to AV media, convert themselves to CALL technologies;

4) CALL natives, i.e., those who from the beginning use ICT for learning/ instructional purposes.

Perceptions will be anatomized in terms of their reflections in assumptions, beliefs, and values.

\subsection{The national perception of ET}

At the macro-level, ET is appreciated more for its potential contributions to national education than to its effects on instruction/learning by teachers and

1 The distinction between native and immigrant is inspired by Prensky (2001a, b). 
students. As mentioned before, ET has consistently been seen as possessing modernization power, which is understood to entail improvement and progress. As the repertoire of ET increases, and gets updated, the enrichment and updated complexity are equally welcome and readily incorporated into the existing structure.

The emergence of Web technology has triggered a cyber rush. The Web power of transcending physical space and time, together with a low cost of reproducing and sharing resources, and solutions to some major problems that could be identified to characterize the macro social-educational environment towards the end of the last century in China, to many Chinese elite minds, seemed to be around the corner. The macro-issues were:

1) There were too many people with too little education - the mass illiteracy problem;

2) There were too many people with inadequate education - the inadequacy problem;

3) Schools, colleges and universities were extremely under-funded - "Too many monks with too little porridge" problem, or the insufficiency problem; and

4) University graduates were no longer assigned by the government with life-long jobs - the iron rice bowl-broken problem (for more discussion about these problems see $\mathrm{Gu}, 2006$ ).

Web technology is perceived to contain another power: a liberating power seen positively, or destructive force seen negatively. Formal tertiary education in China takes place in an enclosed environment, often physically protected by four walls with guards at the front entrance checking comings and goings. The physical enclosure is an outward expression of a deeper value of social and educational nature. The enclosed four-walled campus has long been sociologically assigned the roles of (1) offering formal education, particularly knowledge, to its citizens; (2) carrying out research; (3) developing new technology; (4) implementing the belief that the better education leads to better life and social advancement.

As Christensen (2000: 30) rightly points out, "classroom and campus-based instruction" are "established technology", whereas "distance education, typically enabled by the Internet" is "disruptive technology". The formal ivory tower form of education, being accessible as well as affordable only to the luckiest elite, is disrupted by Web-based delivery of educational resources, which - boundless and timeless - opens an unlimited avenue for less lucky ones to enter into the educational system previously denied to them. 


\subsection{The institutional perception of ET}

Educational institutions, e.g., schools, colleges, universities, situated at the meso-level, act as a bridge linking the macro system with educational manpower at the micro ground level. They may see eye-to-eye with the top ideologically, but with different deep motives. Take upgrading existing ET equipment for instance. If there was funding available for application, the meso occupants would be motivated to bid for the money. Take, for another example, the MoE online education initiative mentioned above. The budget for the initiative was very limited, and soon dried out. Only a couple of early birds caught the worm! However, the macro motivated the meso by issuing empowering policies and favourable conditions in annual assessment schemes. Those pilot-trying institutions would make higher scores than those that did not.

This narrative is meant to give a realistic picture so that the perception of ET at the meso-level is properly understood. We should prepare ourselves for the fact that some institutions may appear to act in support of the technology, but more motivated by the consideration of revenue than positive perception of the technology itself.

The meso positive perception of ET's roles directly impacts the allocation of resources within institutions. Similarly, the meso may motivate or demotivate the ground staff with or without a special promotion scheme by awarding or ignoring those adopting ET in their teaching.

\subsection{The ground level perception of ET}

The ground level CALL users, comprising of four groups, bear the immediate impact ET exerts on their way of teaching/learning. Success or failure of ET ultimately depends on their perceptions and corresponding actions. Furthermore, for younger learners, parents' perception of ET is by no means trivial and negligible.

China's traditional mainstream learning can be captured as teacher-led, classroom-dependent, and textbook-based. Syllabi are pre-arranged with timetables fixed, and students and staff are all allocated to their places. In short everything is supposed to be carried out in an orderly, procedure-like manner with maximum convenience: Classrooms, the library, labs, AV centers, the clinic, functionary offices, sports facilities, shops, dining halls, groceries, restaurants, student dormitories, staff residents, etc. are all provided and within walking distance. In this system the role of academics is to feed the knowledge-hungry students, and the role of administrators is to make all the necessary 
arrangements for both students and academic staff so the latter can concentrate on learning and teaching with minimum distraction.

This is the established environment in which paper-pen conservatives, and AV natives (including staff and students) are customized, routinized and habituated, hence feeling at home. All were disrupted when CALL came. Early digital multimedia CALL was less disruptive and quickly won AV-CALL immigrants, since digital multimedia was in fact an incremental improvement to AV multimedia, which was cumbersome and extremely difficult to edit, copy and share. Staff members were often assisted by technicians, and could hardly be called dedicated AV-CALL immigrants. Some resistance to CALL is derived from the cost of learning it. Students, in contrast, soon surpassed their teachers and became CALL natives, abandoning AV altogether.

Web-based delivery of educational resources is not all that rosy to some learners. Campus education means many things in one basket. Students have direct access to teachers, learning facilities, peers and friends. To some students it also means getting away from poor and underdeveloped hometown. This in turn means gaining access to social mobility and a step up on the ladder of social stratification. So Web-based learning only is not ideal to some learners.

Parents generally pay little attention to the roles AV or CALL plays on campus education, and may be labeled as AV- or CALL standby observers. However, they hold campus education responsible for the following: (1) Providing their offspring with qualified staff and facilities; (2) Keeping their offspring engaged in learning; (3) Making their offspring acquire the prescribed knowledge and skill; (4) Making sure that their offspring be awarded with the prescribed degree or certificate; (5) Protecting their offspring from ill or undesirable influence; (6) Providing personal security.

Parents' such perception of campus education has been seriously disturbed by the campus lockdown due to Covid-19 pandemic. Homes were all of a sudden forced to become "classrooms" that were supposed to be installed with all the digital gadgets and networks that enable CALL delivery. Although CALL programmes in China were required to be provided free, consider those families that cannot afford to buy the necessary hardware in the first place. Furthermore, parents are not usually ICT technicians by trade, so their frustrations with CALL are not difficult to imagine.

\subsection{The early ChinaCALL in retrospection}

As president of ChinaCALL, I have made a rule that I must engage myself in constant critical reviews of what we have been doing with ET. In actual practice, 
critical reviews have been conducted at every five-year interval (see further discussion in Section 6 below). The ICT initiatives, no doubt well motivated and praiseworthy, offered potential solutions to the existing problems, while simultaneously creating problems of their own, which I addressed in one of my reviews (Gu, 2003). Herein one problem and one fallacy are included for those who might be interested.

The problem is termed "instant return problem". As mentioned in Section 3.4 above, business sectors in the pilot phase were allowed to invest in developing ICT applications for education. They were even allowed to take part in running online education institutions. It turned out that they were more interested in the number of students than in the delivery of quality education. Some institutions ended up with more students than they could possibly cope with. Students were only given poor quality CD-ROMs, with no other support whatsoever. Cases like this have done online education more harm than good.

The fallacy is called "fallacy of transferring traditional materials to online delivery verbatim”. The ICT initiatives created an environment in which the universities that competed for MoE endorsement to establish e-learning faculties were motivated more by vogue than by an insightful understanding of the technology. Research into the nature of what ICT could really do for education has remained superficial and anecdotal. The majority of online programmes were, at best, products of the simplistic transference of traditional classroom materials to online delivery, with little understanding that learning facing a computer is substantially different from learning facing a teacher in a classroom.

What has been discussed in this section remains abstract and oversimplified, which is unavoidable for lack of space. To compensate, what follows next presents an in-depth look at a specific instance of ChinaCALL: IBOE. I have chosen it because of my personal intimate knowledge of it. It is intended to be a magnified glance rather than a role model of ChinaCALL.

\section{The Institute of Beiwai Online Education: a case study of ChinaCALL}

IBOE celebrated its twentieth anniversary in 2020. It is instinctive for any institution at this juncture to simultaneously recall its trodden path and look towards its future. Pedagogically, as mentioned in Section 3.1 above, IBOE was a Web-based CALL extension of an existing distance learning programme which had previously been tested and studied by students from all over China between 1995 and 1999 (Gu, 2001, 2008). These years of distance learning experience have rendered us 
much soberer, calmer and wiser in the early days of China's cyber rush. IBOE avoided the simple-minded transference fallacy discussed above. It was keenly aware from the inception that the web-based delivery of existing materials, either traditional classroom based or distance learning based, is never straightforward. Rethinking, redesigning, and fresh testing are required.

\subsection{IBOE: an ecological model}

We started by making a firm distinction between online education (whatever otherwise called) and online learning (whatever otherwise called). The provision of education, online one included, is an organizational action, whereas online learning boils down to an individual learner's behavior. An ecological model of online education was proposed by $\mathrm{Gu}$ (2004, 2005, 2006). Conceptually IBOE comprised six subsystems encapsulated in six English keywords or in 12 Chinese characters (known as the Twelve-Character Guiding Principle): Resource (ziyuan), service (fuwu), process (guocheng), monitoring (jiankong), quality (zhiliang) and outcome (xiaoyi). The interactive relations between these subsystems are visualized in Figure 1.

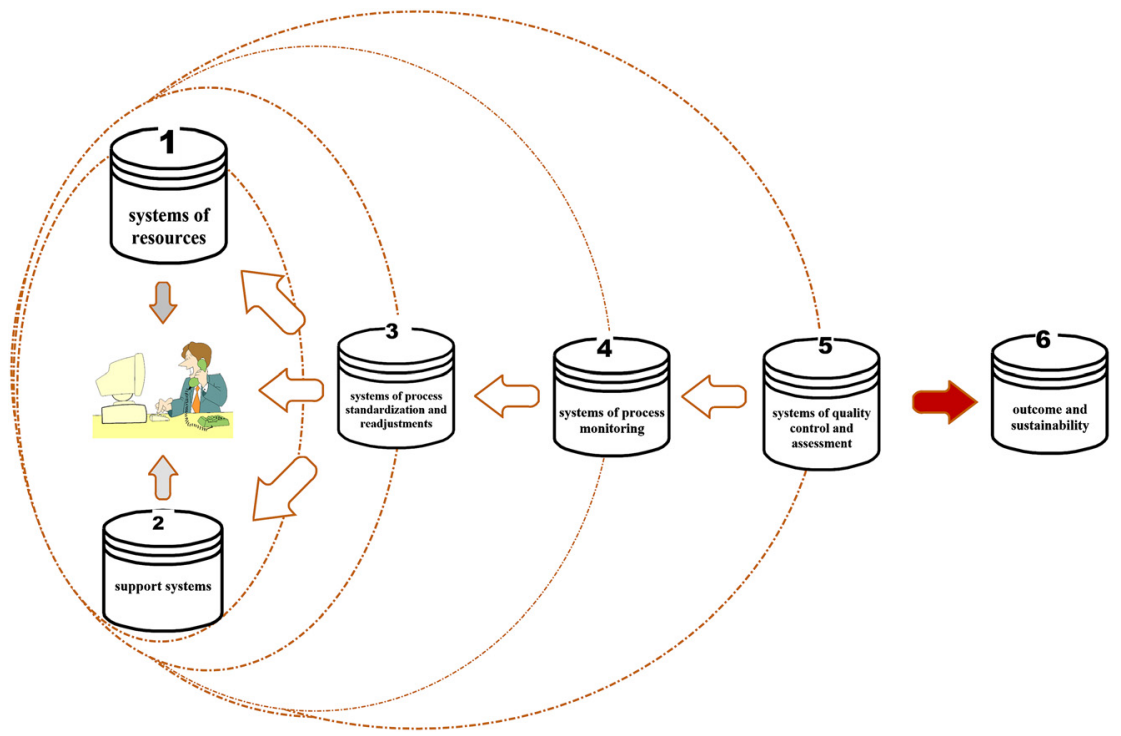

Figure 1: IBOE's six sub-systems (quoted from Gu, 2006, p. 110). 
It is important to note that all the arrows except the rightest converge onto the learner. They indicate the underlying principle of learner-centredness that permeates the first five sub-systems. The fact that the quality control sub-system is placed at the penultimate position may be misinterpreted as being less significant. On the contrary, online education depends on quality for its survival. The rationale for its fifth position embodies our belief that quality is attained and guaranteed when the first four sub-systems are optimally managed. In other words, resource, service, process and monitoring all involve quality issues, and the overall quality of the whole system will be affected by poor performance of any sub-system.

The last outcome subsystem includes pedagogical achievements as well as financial returns. IBOE, one of online education institutions having business sectors as stakeholders, experienced periodic high-level decision-making, and annual budget planning conflicts of interest. The outcome as a subsystem placed outside the elliptical circles does indicate priority given to pedagogical concerns in decision-making and planning.

IBOE learners, unlike campus learners with campus-based and LAN-based learning environments, have two extra environments: the workplace and home. In ecological terms an environment has two general co-circumscribing functions for an inhabitant (in our case a learner): the framing and enabling functions. The framing function consists of constraints or limits the environment imposes on the learner's behaviour. The enabling function, on the other hand, consists of opportunities the environment offers to the learner, who can seize them to achieve what she/he wants. Corresponding with the two general functions, a learner entering the environment will be engaged in two general learning activities, adaptive learning in response to the framing function and active learning in response to the enabling function.

The hybrid environments IBOE learners have to deal with impact the learning outcomes. A learner-centred educational programme, seen in ecological perspective, will start from this simple arithmetic formula about the learner's daily resource expenditure. IBOE learners' daily cognitive resources for learning are measured as follows $\mathrm{Gu}$ (2006, p. 112):

Learners' daily learning resources = learners' total limited resourcesexistence resources - maintenance resources - workload resources

This formula does not allow for resources expended on leisure, social activities and healthcare. An ideal educational environment, either a traditional campus or virtual e-learning, will be such that it will make the best use of the daily learning resources and at the same time be energy saving or renewable. 
The emergent property principle, defined by Odum (1983, p. 5), as "an emergent property of an ecological level or unit cannot be predicted from the study of the components of that level or unit”, is applicable to online education and learning. At the institutional level qualities of online education are emergent properties of component subsystems. At the individual learner level, learning is also an emergent property of learners' interactions with the systems. Here the interdependency relations, in terms of framing and enabling effects, among the elements of ecosystems cannot be overemphasized. “Our goal”, Gu (2006, p. 118) writes, "is to construct and maintain a harmonious and well-balanced e-learning eco-environment, which is both effective and learning resources friendly, then e-learning will take care of itself!" 15 years have passed since; this goal remains some distance away.

The emergent property principle, if applied, entails a crucial implication for online education stakeholders. As mentioned above, online learning in the last analysis is the matter of the learners themselves. You can lead the horse to the river side, but you cannot make it drink, as the English proverb says,. However, according to the emergent property principle, stakeholders are equally responsible for the learner's learning outcome. Any failure on the learner's side is also a failure of the system, no more no less!

\subsection{IBOE: platform modeling}

Platform (pingtai) and courseware (kejian) designate two basic concepts Chinese ICT developers employ in their modeling and design practice. Platform is used either to refer to the underlying hardware or software system, e.g., a Window or Macintosh platform, or to a supporting interface consisting of a package of technologies through which learning materials are delivered. Courseware, the word blending course and (soft)ware, is a platform-supported package of digital resources designed for specific pedagogical goals. This subsection discusses IBOE's practice of platform modeling.

We distinguished two platforms: educational management system (EMS), and content management system (CMS). The EMS and CMS jointly materialise the first five subsystems. To date, IBOE's EMS platform (www.beiwaionline.com), now in version 6 , has stood the test of time and proved to be quite robust. It has also successfully been transferred from an assembly of physical servers to Cloud computing.

The CMS, on the other hand, remains immature. What the CMS was initially intended to achieve was a web-based production of courseware, in particular multimedia-rich and interactive courseware. It was also hoped that a mature CMS 
would enable learners to construct their own courseware or order courseware to suit their own particular learning style. This has turned out to be technically challenging and costly. The courseware design to be addressed below is not for web-based production. They are produced by employing a mix of tool kits and published on the EMS.

\subsection{IBOE: courseware design}

Courseware, as defined above, plays multiple roles in online education: (1) deliver static instructing/learning materials (analogous to print textbooks); (2) deliver dynamic instructing/learning materials (analogous to AV materials plus players), (3) enable synchronous/asynchronous access to both. There are six types of courseware design in IBOE.

- Print textbook transfer: A web-based publication of existing print textbooks verbatim. The design, if any, consists of changing the print pages to Web pages plus extra navigation buttons. The content of the former print textbooks remains intact during the transfer process.

- Audio supplement: The practice of adding audio clips to the print textbook transfer design.

- Video supplement: The practice of adding video clips to the print textbook transfer design. Note that video clips naturally include audio input.

As may have become apparent, these three designs so far all keep the content of the print textbook intact. However, from a technological point of view, there is no small improvement to enrich the screen text with audio clips. And to add video streaming technology to the screen text is a major advancement. From a pedagogic point of view, on the other hand, the audio and video enrichment are more often than not treated as something parasitic on the screen text. It is even occasionally only decorative in function. This is why the term "supplement" has been used.

- Classroom teacher model: A practice of video-taping a teacher delivering a lecture and publishing, on the platform, the compressed video images accompanied by Powerpoint presentations. This design, before synchronous web-conference technology is mature as is found today, entails an asynchronous broadcast of a teacher talking to an imagined class - in fact they are talking to a video camera in a studio! Flipped classes are produced in this way. MOOCs are often made using this method of production too. 
- Multimedia rich: A practice of integrating hypertexts with Web-delivered multimedia. In this design, the Web-based version is in some places considerably different from the print textbook version, if there is one. Material developers work in the way more like TV series developers prepare production scripts.

- Learning process model: A practice of selecting and constructing the content according to a projected learner, i.e., a default learner, who is engaged in a goal-directed learning process. Unlike the previous five designs, this design is not based on a traditional print textbook. The units and their contents reflect a learning process through which a default learner, together with his or her fellow study mates, undertakes a self-paced study. Activities and specific learning tasks are constructed to reflect real life situations. The courseware Using the Computer in ELT (Gu, Hall, \& Hall, 2006) has adopted this design, which has proved to be very costly, labour-intensive and only replicated once in another courseware: Chinese Painting: A Window to Chinese Civilization and Culture (Gu \& Zhang, 2015).

There is an overall distinctive designing feature inherited from the former DT-SMTT materials, namely task-based with a built-in teacher's voice. Learning is modeled as a dynamic process comprising a chain of activities/tasks. These activities/tasks are designed as self-contained and self-taught with a virtual teacher popping up from time to time offering help and feedback.

There is another designing feature worth commenting on. All the designs are underlined by the principle of 3-M Learning, viz. Multimodal, Multimedia and Multiple-environment Learning (Gu, 2007a, 2007b). Multimodal stands for the Principle of Multimodality: It is a norm rather than an exception that the learner learns multimodally. That is, in a natural learning environment, there always are two or more sensory modalities being activated and mobilized in learning. In design practice, learning through naturally saturated experience is preferred to less saturated experience. This principle has a maxim (a sub-principle), namely the maxim of multimodal congruence. For instance, as proposed by Mayer (2001: 184), learners "learn better from animation and narration than from animation and on-screen text".

Multimedia content representation is preferred to mono-textual representation. One piece of content is encouraged to be presented in multimedia manner. Mayer (2001, p. 184) attested the following multimedia principle: "Students learn better from words and pictures than from words alone”. Though multimedia representation leads to information redundancy, it is paid off in more saturated learning experience. 
Multiple environments include cross-platforms, on/off campus, on/offline, and home/travel. In design practice, this multiple-environment learning is most technology-heavy, relative to multimodal learning, which is technology-light, but environment-heavy. Inventions of iPads, cellular phones, smart phones, wireless networks, and other wearable devices facilitate this mode of learning.

\subsection{IBOE's learner-support system}

While campus education is traditionally characterized as classroom-based teacher-led education, online education in contrast is digital resource-driven, hence the resource system being the first subsystem in IBOE. Concerning the overall educational system, the more resources the better. This more-better principle does not apply to an individual learner's learning. Learners' cognitive capacity and availability are limited. Gu (2008, p. 9) formulates the Principle of Cognitive Resources thus: (1) The brain/mind is potentially unlimited in intake/ output; (2) The brain/mind is limited in intake/output in a given time-space. Given this limitation, a learner-support system is central to the digital resource-driven education. It is not an optimal learner-support system if the learner is over- or under-resourced.

IBOE's learner-support system is complex. One of its functions is offering cognitive orientation programme, which is promoted as a whole-person development. Learners are given free a mouse pad reminding them of a set of nine qualities for a successful online learner:

1) Be able to learn independently as well as collaboratively;

2) Be capable of self-discipline;

3) Be capable of self-management;

4) Be capable of solving the conflict between study and other commitments;

5) Be capable of self-monitoring;

6) Be capable of initiative-taking;

7) Be confident and persevering;

8) Be capable of developing one's own learning style and strategies;

9) Be able to lead and control.

\subsection{IBOE: some $\mathrm{Al}^{+}$}

Artificial intelligence (AI), thanks to Turing's conceptualization (Turing, 2004 [1950]), embraces as its hallmark the computer's capability of natural language processing, nowadays including speech recognition, synthesis, machine 
translation, and automated human-machine interaction. IBOE has incorporated some AI technologies in its courseware development, e.g., automated speech pronunciation evaluation, and automated assessment and marking. These AI plus components however are not produced in-house. They are imported from a third party, and embedded in the courseware.

\subsection{Recap}

IBOE in the early years enjoyed over 60 partner institutions providing local tutorial supports to learners all over China. For various reasons most these partners have faded out. Fresh innovative ways need to be explored to strengthen the two learner-support and tutor-support sub-systems.

\section{ChinaCALL in retrospect}

He (2016, pp. 5-11) reviewing the global practice of ET, characterised it in terms of three phases of development, typically found in the USA: (1) focus on infrastructure development from the early 1990s to the late 1990s of the last century; (2) focus on pedagogical applications from the late 1990s to the year 2008; (3) a new phase of critical reflections and innovative adventures beginning in 2009. He argues that the three-phase development pattern holds true of China's context, except for the third, for China's critical reflections began one or two years later than the Western world.

In our three-level structure, He's review is primarily made at the macro level. ChinaCALL, conceptually a subsystem of China's ET, stays outside his concern. Nevertheless, critical reviews of ChinaCALL practice have indeed been conducted periodically by the government offices. The latest one was made under the auspice of the MoE in 2020 to mark the twentieth anniversary of the online education initiatives. While achievements are appreciated, failures as well as misconducts are acknowledged. It is inappropriate and less interesting to verbalise these practicalities here. What I propose to do is reflect philosophically on some fundamental issues regarding CALL and ChinaCALL in particular.

Critical reflections will be made primarily on the practices technologies have been applied to CALL development, and only some passing comments will be offered on future technologies. Flavin (2017, p. 4) rightly points out that "practice is primary. An approach to technology enhanced learning based on practice, rather than on the intrinsic qualities of technologies, enables and encourages engagement with disruptive technologies to support learning and teaching." 


\subsection{ChinaCALL and laws of learning}

CALL has been with us well over 70 years in the global context. Its path has never been smooth. It never has been short of enthusiasts as well as conservatives. We have above differentiated five groups: paper-pen conservatives, AV natives, AV-CALL immigrants, CALL natives and AV-CALL standby observers. With this variety of technology consumers in mind, my reflection starts by posing a fundamental question: What differences does CALL make to learning/instruction in general? Or put it in another way: What differences will CALL make if it is taken away from learning/instruction in general?

Laws of learning: It is a historical fact that learning/instruction can take place without CALL of whatever kind. It is also a fact that learners can learn without a teacher. For ease of reference I call it basic learning ( $\mathrm{Gu}$ [2008] called it pure learning) so that it can be contrasted with mediated learning, i.e. the learner being assisted in learning. Regarding basic learning, there are some fundamental "facts", which might very well be couched in "law".

- The Law of Experiential Process: Experiential designates interactions between the learner and the internal/external environment of whatever kind. Take a newborn baby born with the instinctive behaviour of rooting, which enables the baby to interact with the mum's breast or any make-do object. This experiential learning is crucial both for survival and for sustaining the rooting instinct. Process designates an event that has a start point, an end point, and some time interval in between. In other words, experiential learning of whatever kind has an intrinsic property of duration, which may last in terms of milliseconds, or of years.

- The temporality of learning entails: (1) Learning increments with time - the more time one spends on learning, the more the learner learns, hence life-long learning. In view of human mental capacity, there seems to be no point at which the learner's brain is too full to learn. (2) Learning decays over time human memory and physiological built-up change over time, which affects what has been learned. Non-stop practice or constant use resists natural decay over time.

- The Law of Internalization: Since learning is interactive by nature according to the Law of Experiential Process, it has to be internalised by the learner, e.g. memorization, motor-automatization, etc. To adopt Lefrancois' definition, learning occurs when "relatively permanent changes in potential for behavior that result from experience but are not due to fatigue, maturation, drugs, injury, or disease." (Lefrancois, 2000, p. 5). "Relatively permanent changes in potential for behavor" cannot occur without internalization. 
- The Law of Irreplaceability: Just as no one can eat for someone else, so no one can learn for another. This law is an entailment of the Internalization Law, that is, no one can internalise learning for someone else.

- The Law of Erasibility: Learning is not something that, once achieved, can be owned by the learner forever. It can be erased. This is logically derived from the Experiential Process Law. As a process, learning is dynamic, and cannot be a substantial object built with an ever-lasting material.

The word "law" is deliberately chosen for a rhetorical purpose with Chinese learners in mind. In our field studies of Chinese foreign language learners, we often are bombarded with questions such as: "Teacher, I have no time to learn English. Can I learn it fast?" - as if they could violate the Experiential Process Law; "Teacher, please just tell us what's going to be examined." - as if they could violate the Laws of Internalisation and Irreplaceability; "Teacher, why do I keep forgetting what has been learned?" - as if they could violate the Erasibility Law. When we explain to learners why they cannot do, the evoking of law-image carries some rhetorical force that is otherwise absent.

Let us come back to the question raised earlier: What differences does CALL make to learning/instruction? Or what differences will CALL make if it is taken away from learning/instruction? The two issues will be referenced below as facilitation potential and deprivation potential respectively. These two questions now can be answered by asking another question: In what way does CALL affect the four laws above? For the sake of space, I shall simplify the discussion by bringing in only two dimensions: CALL as medium of learning/instruction on the one hand, and the four groups of users on the other.

\subsection{CALL as medium of learning}

For AV natives, it is obvious that they had learned everything alright before CALL was invented. CALL facilitation or deprivation potentials are irrelevant. When CALL came to them, the CALL itself became an object of learning. This experiential process of learning CALL is governed by the four laws. In other words, CALL had to be experienced, internalised, kept using it in order not to erase it. This will incur a sharp learning curve. Interestingly, institutions, workplaces and even families literally appoint technicians to do CALL-related jobs, which is a flagrant violation of the Internalization and Irreplaceability Laws. The penalty for the violation is that AV-native culprits stay outside CALL or fake CALL users.

For those AV-CALL immigrants, CALL becomes a medium of learning to other content acquisition. Let us consider a case provoking the first law. The CALL now 
stands in between the experiencer and the learning object to be experienced. Ideally, CALL should be transparent, that is, CALL is no longer being experienced as an object of learning itself. Sadly, this is often not the case. Lost links, failure of the system, unwanted hits, etc., etc., render CALL as a medium of opaque learning and a source of frustration.

Does CALL facilitate the learner's internalisation (the second law)? This is not quite so even to veteran users. It does so only to some tasks, whereas to others it can do some disservice.

Can CALL replace human learners in some tasks? Yes, it can, e.g., automatic marking. But remember that what CALL replaces is not human learning, which can never be done, but some jobs human learners are supposed to do.

Could the word never be challenged eventually by the advances made in digital neuroscience and AI? Now neural prosthetics seems to trigger promises that go beyond ordinary imagination. Artificial neural circuits bearing CALL content could in theory be implanted into the brain. Through some brain-computer interfaces the devices would literally "learn a language" (i.e. activates the language knowledge stored) for the implanted learner. Should this become true, the four laws of learning would be truly flouted, and CALL would be so advanced that the user would not have to learn any language at all. AI-supported machine translation systems nowadays seem to offer technologies that are so disruptive that would derail language-specialized universities such as BFSU.

The law of irreplaceability dictates that CALL of whatever kind cannot learn for the learner, which means that CALL is destined to act as an assistant, a learningenhancing artifact to learning. CALL is therefore destined to be operative in the learner's learning process (the law of experiential process). Does CALL enhance or diminish the learner's internalization? This is one of the areas where CALL is considered to be a two-blaze sword: It can either enhance or diminish internationalization, depending on the way it is designed and adapted to.

CALL's capacity to transcend physical space and time is the greatest attraction to both policymakers and educationalists, as it offers opportunities for life-long and continued learning. So if CALL is said to have any long-term effects on learning, it is its effect on the principle of temporality. The former sharp division between learning first and work afterwards for the rest of life is seriously undermined by CALL.

So far we have dealt with CALL's relations with all the laws and principles of learning except for two: the law of erasibility and the principle of cognitive resources. Does CALL have any effect on them? Can CALL help the learner recover what has been erased? Can CALL act as an extra cognitive device that enlarges the learner's cognitive resources? These are empirical questions wanting evidencebased answers. 


\subsection{CALL as medium of instruction}

Historically, interest in CALL seems to be originated in CALL's potential in giving instructions rather than in assisting learning. In 1958, Skinner, for instance, published a paper in Science with the title "Teaching Machines". Ten years later, he published The Technology of Teaching. A computer capable of delivering machine instructions was enthusiastically envisaged as being able eventually to 'teach' a lot of things and to replace human instructors. He observes that "Machine instruction would permit each student to proceed at his own rate." (Skinner, 1968: 30)

With hindsight, we now see clearly that Skinner was over-ambitious. Even today, over 70 years later, with the advancement of digital technologies as no one had ever dreamed of, a machine that can replace a human instructor still does not exit! Is it the case that humans should just be patient? Perhaps it is not a question whether it could ever exist, but whether it is desirable to have such a machine in the first place!

Against the theory of basic learning as depicted above, the role a human teacher plays in the learner's learning is similar to that of CALL, that is, to help the learner learn. As just no teacher can eat for the learner, so the teacher cannot learn for the learner. As simple as that! The fourth design - classroom teacher model design discussed in Section 5.3 above - is a web-based delivery of such teaching. This is not a genuine case of computer-assisted language teaching (CALT). It is more an extension of a traditional classroom teaching from a physical setting to cyberspace.

A genuine case of CALT is what is known as integrated mode of teaching. Roblyer (2005, p. 3) has this to say about integration: "Perhaps the most important - and the most difficult - challenge is for teachers to identify specific teaching and learning problems that technology can help address or how it can create important educational opportunities that did not exist without it.” Tomei's (2007) edited collection of papers is also on integrating technology into the classroom.

Integration touches upon a more deep-seated issue of the relation between learning process and teaching process. From the teacher's perspective, the technology can be involved in two processes: (1) in self-preparation for classroom teaching, or in personal research; (2) in actual classroom teaching. So two modes of integration emerge: personal development integration and classroom integration. In my field interviews with some teachers I was told that the teacher felt that the courseware had rendered them nothing else to do, as if their job of teaching had been pre-emptied by the courseware. The crux of the problem lies in the relation between teaching and learning processes: Should the teacher embed his or her 
teaching process as part of the learner's learning process, rather than the other way round, the problem can easily be solved. To me the teaching process embedded in the learner's learning process is a fruitful step towards a genuine learner-centred education.

\subsection{Recap}

The facilitation potentials of CALL are generally appreciated by AV-CALL immigrants, and taken for granted by CALL natives. The deprivation potentials of CALL remain dormant to these two groups until electric power is cut off, or CALL's infrastructure breaks down, or hard drives and flash memory disks containing PPTs are corrupted. In my case, I cannot even "live” without e-books. I buy paper books, scan them and read the screen texts. I cannot imagine that I can do any research or teaching without access to my personal e-library and the corpora I have compiled. To me, the deprivation potential of CALL would be unbearable.

\section{ChinaCALL prospect}

Selwyn (2010, p. xx) remarks: "Commenting on the future of education and technology is a perilous pastime. Even the most informed commentators find technological forecasting to be a tricky business.” Meanwhile I am sympathetic with Selwyn's observation, I still feel there is something solid and stable on which sensible predictions can be made. Our predictions are to be partitioned consistently following the tripartite macro-meso-ground scheme.

The macro level: socioeconomic, political, cultural system

The Chinese faith and trust in technological advancement and its impact on national development in all walks of life has remained strong and unwavering. What is even more encouraging is that the promotion of educational technologies, and $\mathrm{AI}$ in particular, is regarded as part of China's blueprints of developmental strategies for the new millennium.

The meso level: institutions, organizations, ICT providers

The blueprints and strategies for technological development drawn at the macro level depends on the meso level to implement them, i.e., to convert them into social/technical products and practices. In a sense, they directly benefit from 
national policies and investments. Their future commitments to ICT projects, and ChinaCALL in particular are quite secure.

The ground level: technology consumers

Covid-19 Pandemic, playing havoc with all walks of life, has created an unprecedented demand for Web and mobile technologies. Smart phones installed with all sorts of applications have become indispensable part of one's identity. Campuses are locked down, and instructions/learning are delivered online. All the CALL programmes in China have been required to be provided free for a certain period. The former paper-pen conservatives and AV natives alike were trained to become CALL immigrants. The former AV-CALL immigrants become CALL devotees. The former CALL natives are reinforced and become expert users.

What is remarkable is that some CALL natives may well be characterised as what Dingli and Seychell (2015, p. 2) call "second generation of Digital Natives". Their proficiency of using CALL technologies tend to surpass their teachers/tutors. As pointed out by Roblyer (2005: 52), “[m]any educators now believe that the world is changing too quickly to define education in terms of specific information or skills; they believe education should focus on more general capabilities such as "learning to learn" skills that will help future citizens cope with inevitable technological change." To the best of my knowledge as well as the hunches I have gained in my 20 years' experience in managing an online education institute, blended learning and teaching are the directions of the future. Technologies may eventually reach the stage when they can do anything people want them to, but this capacity will be irrelevant. What will be at issue is whether it is desirable to employ them when, where, how, to whom, and for what purpose.

I would like to conclude this paper by proposing a mental experiment. What will be left to the learner/teacher after CAI, CALT, CALL, CAT, Mobile Learning, etc., are automatised and made artificially superintelligent by AI? By then, will it be the case, to borrow Ramge's wording about AI ("human asks, machine answers”), that learners ask, CALL delivers? Once AI's "superintelligence”, as Bostrom (2014) envisages, wipes out the four laws of learning, will, I would quickly ask, there be any human intelligence left?

\section{References}

Benson, P., \& Voller, P. (1997). Autonomy and independence in language learning. London: Longman.

Bostrom, N. (2014). Superintelligence: Paths, dangers, strategies. Oxford: Oxford University Press. 
Christensen, C. M. (2000). The innovator's dilemma: When new technologies cause great firms to fail. Boston: Harvard Business School Publishing.

Dingli, A., \& Seychell, D. (2015). The new digital natives: Cutting the chord. Heidelberg: Springer.

Esch, E. (1994). Self-access and the adult language learner. Centre for Information on Language Teaching and Research. London: Bourne Press Ltd.

Flavin, M. (2017). Disruptive technology enhanced learning: The use and misuse of digital technologies in higher education. London: Palgrave.

Gardner, D., \& Miller, L. (1999). Establishing self-access: From theory to practice. Cambridge: Cambridge University Press.

Gu, Y. G. (2001). From the classroom to distance to Internet. ELT in China, 3, 128-142.

Gu, Y. G. (2003). ICT the latest educational initiatives in China: A critical survey. Invited speech at EMINENT Conference in Geneva on 8th-10th Oct 2003.

Gu, Y. G. 顾曰国 (2004). [Exploring online education Volume 1] 《网络教育初探》. Beijing 北京: Foreign Language Teaching and Research Press 外语教学与研究出版社.

Gu, Y. G. 顾曰国 (2005). [Exploring online education Volume 2] 《网络教育初探(续集)》. Beijing 北 京: Foreign Language Teaching and Research Press 外语教学与研究出版社.

Gu, Y. G. (2006). An ecological model of e-learning in a Chinese context. Studies in Continuing Education, 28(2), 99-120.

Gu, Y. G. (2007b). Learning by multimedia and multimodality: Some critical reflections on Webbased courseware design in the Chinese context. In S.-0. Helen (Ed.), e-Learning initiatives in China: Pedagogy, policy and culture (pp. 37-56). Hong Kong: Hong Kong University Press.

Gu, Y. G., Hall, C., \& Hall, E. (2006). Using the computer in ELT: Technology, theory and practice. Beijing: Foreign Language Teaching and Research Press.

Gu, Y. G. 顾曰国 (2007a). [Analyzing multimedia and multimodal learning] 多媒体多模态学习剖 析. Computer-Assisted Foreign Language in China 《外语电化教学》, 114(4), 3-12.

Gu, Y. G. 顾曰国 (2008). Computer-assisted language learning: The state of the art with special reference to the Chinese context. Computer-Assisted Foreign Language in China 《外语电化 教学》, 120(2), 3-13.

Gu, Y. G., 顾曰国 \&, Zhang, S. 张舍茹 (2015). [Chinese painting: A window to Chinese civilization and culture]《中国美术》. Beijing 北京: Foreign Language Teaching and Research Press 外 语教学与研究出版社出版.

He, K. K. 何克抗 (2016). [New developments of educational technology] 《论教育信息化发展新阶 段》. Beijing 北京: Beijing Normal University Publishing Group 北京师范大学出版集团.

Huang, Y. Y., 黄月园 \& Gu, Y. G. 顾曰国 (1996). [An integrated approach to self-access learning] 以 学生为中心, 多维一体的大学英语教学法. Foreign Language Teaching and Research 《外语 教学与研究》, 106(2), 9-13.

Kalz, M., Yasemin, B., \& Marcus, S. (2014). Mobile as mainstream - Towards future challenges in mobile learning. Switzerland: Springer International Publishing.

Kang, F. Y., \& Song, G. S. (2007). e-Learning in higher education in China: An overview. In S.-O. Helen (Ed.), e-Learning Initiatives in China: Pedagogy, policy and culture (pp. 11-32). Hong Kong: Hong Kong University Press.

Kinshuk (2009). Foreword. In R. Hokyoung, \& D. Parsons (Eds.), Innovative mobile learning: Techniques and technologies (pp. xii-xiii). Hershey: Information Science Reference.

Lefrancois, G. R. (2000). Theories of human learning: What the old man said (4th ed.). Australia: Wadsworth.

Levy, M. (1997). Computer-assisted language learning. Oxford: Clarendon Press. 
Liu, G. 刘光 (1990). [Higher education Annals in new China]《新中国高等教育大事记》.

Changchun 长春: Northeast Normal University Press 东北师范大学出版社.

Liu, G. 刘甘娜(1988). [Computer-assisted instruction]《计算机辅助教学》. Beijing 北京: Higher Education Press 高等教育出版社.

Mayer, R. E. (2001). Multimedia learning. Cambridge: Cambridge University Press.

Odum, E. P. (1983). Basic ecology. Philadelphia: Saunders College Publishing.

Pomerol, J.-C., Epelboin, Y., \& Thoury, C. (2015). MOOCS: Design, use and business models. London: ISTE Ltd.

Prensky, M. (2001a). Digital natives, digital immigrants Part 1. On the Horizon, 9(5), 2-6.

Prensky, M. (2001b). Digital natives, digital immigrants Part 2: Do they really think differently? On the Horizon, 9(6), 1-6.

Roblyer, M. D. (2005). Integrating educational technology into teaching. $\mathrm{Xi}+\mathrm{IBk}$-an: Pearson Education Asia Limited and Shaanxi Normal University Press.

Selwyn, N. (2010). Foreword. In E. Martin, \& M. Schiefner (Eds.), Looking toward the future of technology-enhanced education: Ubiquitous learning and the digital native (pp. $\mathrm{xx}-\mathrm{xxi}$ ). Hershey: Information Science Reference.

Shi, S. 师书恩 (2001). [Computer-assisted instruction] 《计算机辅助教学》. Beijing 北京: Higher Education Press 高等教育出版社.

Skinner, B. F. (1958). Teaching machines. Science, 128, 969-977.

Skinner, B. F. (1968). The technology of teaching. New York: Appleton-Century-Crofts.

Tomei, L. (2007). Integrating information and communications technologies into the classroom. London: Information Science Publishing.

Turing, A. M. (2004) [1950]. Computing machinery and intelligence. In Mind, volume LIX, number 236 (pp. 433-460), 1950. Reprinted in Shieber, S. M. (2004). The turing test: Verbal behavior as the hallmark of intelligence (pp. 67-96). London: The MIT Press.

Xiao, S. Z. 萧树滋 (1983). AV Education《电化教育》. Shijiazhuang 石家庄: Hebei People's Publishing House 河北人民出版社.

\section{Bionote}

\section{Yueguo Gu}

Beijing Foreign Studies University, Beijing, China

gyg@beiwaionline.com

Yueguo Gu M.A., Ph.D., Dr. Lit honoris causa (Lancaster University), is a leading researcher of Artificial Intelligence and Human Languages Lab, Beijing Foreign Studies University. He is President of ChinaCALL Association, Director of China Multimodal, Multimedia and MultiEnvironment Research Centre, and Director of Ageing, Language and Care Research Centre, Tongji University. His research interest includes pragmatics, discourse analysis, corpus linguistics and online education. 